\title{
DE LAVRADORES A PESCADORES ARTESANAIS: CAMPONESES
}

Joenes Antônio Guimarães Pereira*

Dalva Maria da Mota**

Resumo: O objetivo deste artigo é analisar a influência de um programa de política pública motivado por preocupações ambientais - a Política do Seguro Desemprego ao Pescador Artesanal (PSDPA) - para a reprodução social de camponeses no Pará. A pesquisa foi realizada por meio de um estudo de caso e os procedimentos utilizados foram observações e entrevistas com questionários e roteiro aberto com moradores afiliados e não afiliados à Colônia de Pescadores, beneficiários ou não do Seguro-Defeso. As principais conclusões mostram que os recursos oriundos do Seguro-Defeso foram utilizados diretamente na reprodução social de ciclo curto e geracional, alcançando as atividades realizadas na pesca, na agricultura, no beneficiamento de produtos e no comércio. Na pesca, o maior investimento concentrou-se tanto para diminuir as dificuldades do trabalho quanto para justificar a autodesignação de pescador artesanal. $\mathrm{Na}$ agricultura, os recursos foram destinados à intensificação da capacidade de implantação de roças. No beneficiamento, o processamento da farinha e do açaí, combinando o conhecimento tradicional com recursos tecnológicos disponíveis no formato de máquinas, contribuiu para tornar os processos menos penosos e mais eficientes quanto ao volume de processamento. No comércio, a disponibilidade do recurso incentivou iniciativas de comercialização (açaí, frango e "casquinhos"). As atividades compõem arranjos cujos propósitos são, no curto prazo, o aprovisionamento do grupo doméstico e, no longo prazo, a estabilidade indispensável à reprodução social como camponeses que realizam inúmeras atividades.

Palavras-chave: Seguro-Defeso. Pescadores artesanais. Reprodução social.

\begin{abstract}
The aim of this article is to analyze the influence of a public policy program based on environmental concerns - The Income Support for Artisanal Fishermen (PSDPA) - whose aim is to ensure the social reproduction of peasants in the state of Pará. This research is based on a case study involving the following procedures: observations and interviews using questionnaires and open script questions with residents - members and non-members - of the local fishermen's colony, including both beneficiaries and non-beneficiaries of the Closure Period Benefit. The main conclusions are that closure period benefit resources are directly used in both closed circuit and generational social reproduction, involving fishing and agricultural activities, as well as in the processing and trading of products. In fishing, resources are mainly used to reduce hardship and justify (self) designation as artisanal fishermen. In agriculture, they are used for boosting and expanding the implementation of shift cultivation activities. In addition, resources are used for flour-making and açai processing, combining traditional knowledge and available technology, such as machines, making processes more straightforward and efficient, as well as increasing the volume of production. In terms of trade, resources are used to promote marketing initiatives (for açai, chicken and canoes). The short-term aim of these activities is to support households, while in the long-term to provide indispensable stability to the social reproduction of peasants who carry out a wide range of activities.
\end{abstract}

Key Words: Closure Period Benefit. Artisanal Fishermen. Social Reproduction.

\footnotetext{
* Mestre em Agriculturas Familiares e Desenvolvimento Sustentável da UFPA. Indigenista Especializado, Coordenação Técnica da FUNAI em Oiapoque. E-mail: joenes.pereira@,funai.gov.br.

** Doutora em Sociologia, pesquisadora da Embrapa Amazônia Oriental, em Belém (PA), bolsista de produtividade do CNPq. E-mail: dalva.mota@embrapa.br.
} 
poração criativa nas políticas públicas, das propostas, expectativas e demandas formuladas por grupos rurais, na pesca, na agricultura ou no agroextrativismo (HÉBETTE; MAGALHÃES; MANESCHY, 2002, p. 33).

tratégias de reprodução social de grupos camponeses no decorrer do desenvolvimento de um programa de política pública, qual seja o Seguro Desemprego do Pescador Artesanal- SDPA.

Cabe destacar algumas características essenciais dos grupos camponeses, tais como a importância da organização social e de trabalho fundamentada na família, as relações de interconhecimento, importância do parentesco e vizinhança, o controle relativo dos meios de produção e a relativa autonomia em relação à sociedade global (MOREIRA; HÉBETTE, 2009; SABOURIN, 2009; GODOI; MENEZES; MARIN, 2009 e ALMEIDA, 2010). Na Amazônia, o campesinato tem como característica marcante a realização simultânea de atividades na terra, no rio e na floresta, valendo-se das relações sociais próprias do grupo, do trabalho com o meio ambiente e das políticas públicas que afetam o cotidiano. Vivencia assim uma diversidade de situações, correlacionada à condição de extrativistas, agroextrativistas, ribeirinhos, pescadores artesanais, dentre outros (GODOI; MENEZES; MARIN, 2009; MOREIRA; HÉBETTE, 2009). Como destacado por estudiosos:

[...] é necessário compreender a diversidade de situações de vida dos muitos tipos de pequenos produtores que combinam atividades econômicas ou são especializados, com maior ou menor grau de intervenção e transformação do meio ambiente. Para tal é imperativo considerar as dimensões históricas e culturais. Suas trajetórias são variadas. Partilham como eixo comum, sem dúvida, a progressiva construção de espaços públicos de resistência, de organização coletiva e de elaboração de projetos comuns. Expressões como 'conservação produtiva' (HALL, 2000), 'modernização forçada' (BRITO, 2001) e 'campesinato ecológico' (SAWYER, 1996) chamam a atenção para a necessidade da incor-
Com base no conhecimento sobre os recursos naturais nos ambientes da várzea, rios e mata, os camponeses amazônicos desenvolvem uma gama de atividades, sendo essa polivalência o capital social do homem amazônico (MAIA, 2009). As atividades mais recorrentes são o extrativismo vegetal, extrativismo animal (caça e pesca), pequenas criações, plan(WAGLEY, 1998; PINTOM; EMPERAIRE, 2004; CARNEIRO et alii, 2007; MOREIRA, 2009), existindo sempre uma atividade que se sobressai (MAIA, 2009). No caso desta pesquisa, essa atividade é a plantação de mandioca para a produção de farinha.

O conhecimento dos ambientes amazônicos, assim como das formas de trabalho adaptadas a esses ambientes de acordo com sua sazonalidade e voltadas ao atendimento de suas necessidades, é em grande medida um legado dos povos indígenas originários dessa região (WAGLEY, 1998; FRAXE, 2011), relevante para sua existência e continuidade. Mais recentemente, os camponeses desenvolveram estratégias diferenciadas no quadro de oportunidades ao qual têm acesso, no interior do qual se situam as iniciativas de políticas públicas.

Tendo em conta esse debate, o objetivo do artigo é analisar a influência de um programa de política pública motivado por preocupações ambientais - o PSDPA - no processo de reprodução social em um grupo camponês amazônico. Interessa-nos, particularmente, neste artigo, responder às seguintes questões: 1) Como a afiliação à Colônia de Pescadores e o recebimento do Seguro-Defeso interferiram nos processos produtivos e comerciais deste grupo camponês? e 2) Quais os reflexos dessa afiliação na gestão tações de frutíferas e as plantações de espécies anuais 
da reprodução social desse grupo?

A pesquisa foi realizada por meio de um estudo de caso com observações e entrevistas com membros de $63 \%$ dos grupos domésticos ali residentes. Realizamos também trinta e três entrevistas semiestruturadas com moradores, afiliados e não afiliados à Colônia de Pescadores na localidade Rio de Peixes ${ }^{1}$, no Pará. Privilegiamos na análise uma localidade ribeirinha com cinquenta e oito grupos domésticos, dos quais $67 \%$ vivem à margem do rio (na "beira") e 33\%, no centro (distante do rio).

Em meados da década de 2000, a principal atividade era a agricultura para a produção de mandioca a ser transformada em farinha, comercializada principalmente por meio de marreteiros que ali chegavam de barcos. Eram também muito frequentes atividades como a pesca, a caça e a coleta de produtos na floresta por adultos e crianças, segundo a época. Não obstante o conjunto de atividades interconexas, a autodenominação de lavradores(as) predominava localmente, a ponto de definir a sua inclusão na denominação da associação local naquela época. Por ocasião de nosso retorno a partir de 2011, observamos mudança na autodesignação, com os adultos se identificando como pescadores(as) em correspondência à afiliação à Colônia de Pescadores. Na ocasião, uma média de 37\% do total das pessoas com mais de vinte e menos de cinquenta e nove anos estavam afiliados à colônia. $\mathrm{Na}$ faixa etária de trinta a trinta e nove anos, esse valor sobe para mais de $56 \%$, tendo muitos desses trabalho regular sem carteira assinada em outras atividades.

1. Estratégias de reprodução social

Segundo Almeida (1986), estratégias adotadas

${ }^{1}$ Preferimos não identificar o município e atribuir nomes fictícios ao lugar onde o estudo de caso foi realizado, denominado Rio de Peixes, e aos entrevistados, para os quais utilizaremos siglas. "combinando trabalho, recursos naturais e conhecimento tradicional para atender ao consumo familiar e para repor os insumos necessários ao reinício do processo" estão envolvidas na reprodução de ciclo curto, anual, enquanto outras, de fundo extra econômico, são voltadas à reprodução ao nível geracional, ligadas ao ciclo longo de reprodução. Dessa forma, "famílias adotam estratégias micro (de curto e de longo prazo) como resposta a pressões macroeconômicas e políticas (preços, leis)" (ALMEIDA, 1986, p. 67).

É a visão sobre o desempenho familiar e individual na reprodução das classes sociais que dá início às pesquisas sobre as estratégias familiares de sobrevivência ou reprodução (OLIVEIRA, 1985 apud GARCIA; OLIVEIRA, 2006). De uma maneira geral, as estratégias de reprodução social remetem ao conjunto de escolhas que se desenvolvem nas unidades domésticas para garantir sua manutenção cotidiana e geracional (GARCIA; OLIVEIRA, 2006).

$\mathrm{Na}$ literatura, o conceito de estratégias de reprodução social é suficientemente abrangente para elucidar as questões referentes às escolhas familiares que visam à manutenção cotidiana e geracional das mesmas. De acordo com Schneider (2003), há consenso dentre os estudiosos da Sociologia da Agricultura de que os agricultores familiares têm uma diversidade de situações e adotam múltiplas estratégias de reprodução social, por isso:

[...] as decisões tomadas pela família e pelo grupo doméstico ante as condições materiais e o ambiente social e econômico são cruciais e definidoras das trajetórias e estratégias que viabilizam ou não sua sobrevivência social, econômica, cultural e moral (SCHNEIDER, 2003, p. 19).

As estratégias de reprodução social vêm sendo estudadas, então, seja como um conjunto de atividades, respostas, ações ou simplesmente opções, mas sempre remetem a uma expectativa de progressivida- 
de social, a partir de um determinado grupo doméstico, família, grupo familiar ou comunidade.

É importante ressaltar que existe certa insuficiência na literatura acerca do tema da utilização do Seguro-Defeso e das relações que vêm trazendo a política pública que o institui, principalmente quando considerada a inserção de membros de comunidades onde coexistem diversas atividades produtivas $\mathrm{e}$ de extrativismo, sendo a principal a produção de farinha de mandioca. Dessa forma, a pesquisa aqui apresentada assume relevância dentro do estudo da agricultura familiar e do campesinato no Brasil pela possibilidade de oferecer subsídios sobre como políticas sociais e ações afirmativas, como a Política Pública da Seguridade Social do Pescador Artesanal, podem influenciar na reprodução social de grupos domésticos camponeses em uma localidade ribeirinha da Amazônia.

\section{A PSDPA NA AMAZÔNIA}

O Seguro-Defeso foi instituído com a promulgação da Lei n. ${ }^{\circ} 8.213$, de 25 de julho de 1991, que incluiu os pescadores artesanais entre os segurados especiais, considerados aqueles que, "individualmente ou em regime familiar", fazem da pesca sua "profissão habitual ou principal meio de vida", desde que respeitadas algumas outras características. Foi motivado por precauções ambientais, sendo empregado o Seguro-Defeso para garantir a paralisação da pesca no período do defeso pelos pescadores artesanais que fazem dessa atividade seu principal meio de vida. Para isso, concede aos pescadores um salário mínimo a cada mês em que eles estejam impedidos legalmente de realizar seu ofício para suprir suas necessidades durante a época do defeso.

A noção de defeso é regulada pelo Instituto Brasileiro do Meio Ambiente e dos Recursos Naturais
Renováveis (IBAMA) de acordo com as particularidades das espécies e das regiões do país. Para o caso em análise, o defeso alcança o período de novembro a fevereiro e totaliza quatro meses. É exatamente nesses meses que o pescador artesanal afiliado é considerado apto a recebê-lo, ou seja, usufrui do benefício.

Normativamente ${ }^{2}$ são pescadores profissionais na pesca artesanal aqueles "que exerçam a pesca como atividade principal e com fins comerciais, fazendo dessa atividade sua profissão e principal meio de vida", sendo ainda necessária a "comprovação de que não há qualquer vínculo empregatício em outra atividade profissional que não seja a de pesca, [...] e a verificação de que não há outra atividade econômica não relacionada diretamente com a atividade de pesca, mesmo que sem vínculo empregatício". Não obstante a legalidade, a classificação utilizada na legislação da pesca artesanal é insatisfatória porque no dia-a-dia, “inclui, também, grupos como pescadores-lavradores, categoria na qual estão os ribeirinhos que praticam pesca, agricultura e coleta, em bases sazonais e permanentes, sendo a família a base da produção, e a pesca, um dentre os seus vários meios de vida". (LOURENÇO; HENKEL; MANESCHY, 2006, p. 4).

A legislação indica a especialização e exercício de uma atividade sem correspondência com a realidade por nós observada, em que múltiplas atividades econômicas e inserções no mercado de trabalho se alternam, além da pesca. Estratégias de pluriatividade são citadas por autores que apontam que "pescadores na busca pela reprodução social combinam atividades pesqueiras e não-pesqueiras" (COTRIM; MIGUEL, 2008, p.14). Para Nierdele et alii (2005, p. 4), existem “elementos suficientes para identificar o pescador artesanal como uma forma peculiar de produção, a qual se aproxima dos traços gerais que definem a agricultura familiar", sendo a adoção de diferentes estratégias uma prática cotidiana.

\footnotetext{
${ }^{2}$ Instrução Normativa n. ${ }^{\circ} 2$ do Ministério da Pesca e Aquicultura (MPA), publicada em 26 de novembro de 2011.
} 
Segundo o que reza a legislação, os envolvidos no nosso estudo de caso, sem exceção, não seriam pescadores artesanais, uma vez que comercializam produtos da agricultura. Como tal, enquadrar-se-iam na modalidade de pescador não comercial de subsistência, que pesca para o consumo doméstico ou escambo e sem visar lucro, categoria que não teria direito ao Seguro-Defeso (Lei n. ${ }^{\circ} 11.959$, de 29 de junho de 2009). O enquadramento não é consensual no meio acadêmico e McGrath et alii (2008, p.33) sugerem que no contexto amazônico a pesca de subsistência deveria ser considerada uma subcategoria da pesca artesanal, porque a pesca somente para o consumo é rara. Reconhecem os autores o dinamismo da atividade, com pescadores de subsistência comercializando o excedente de suas pescarias e quase todos os pescadores artesanais consumindo boa parte do pescado capturado.

A reinterpretação da lei, localmente, favoreceu a afiliação de uma parte relevante dos adultos de Rio de Peixes à Colônia de Pescadores na condição de pescador artesanal. Em consequência, a Colônia de Pescadores do município, com cerca de cinco anos de fundação, contava com mais de 2.500 filiados em 2012, muitos destes aptos a receber o Seguro-Defeso

A busca por benefício no curto prazo, possível aos pescadores artesanais, foi importante para alavancar localmente não só o programa de política pública, mas também os interesses de agentes governamentais que se casaram com os de dirigentes de colônias. Não passa despercebido que os programas de políticas públicas são implementados por meio "das arenas que por ela e nela se constituem" (NEVES, 2005, p.1). Assim, as interações de atores situados em esferas diferenciadas (agentes governamentais, diretoria da colônia e moradores da localidade de estudo) permitem-nos entender como se deu a entrada dos pescadores nessa organização.

Esse processo teve desdobramentos na arena política, culminando com a cassação de um deputado estadual $^{3}$ e com a acusação de afiliações incentivadas pela diretoria da Colônia de Pescadores relacionada a problemas de uso da entidade para favorecimento político individual, tema tratado por Marinho (2009).

3. Reprodução social COM PSDPA EM RIO DE PEIXES

Estudos mostram que o Seguro-Defeso é de grande importância para as economias locais no meio rural, sobretudo em regiões onde a renda é baixa, e os benefícios sociais são um aporte financeiro considerável para as famílias, como a aposentadoria e a bolsa família (Caldas et alii, 2007; IBASE, 2008; Niederle et alii, 2005) e têm até mesmo contribuído para a melhoria das atividades tradicionalmente realizadas, como é o caso da agricultura.

O aporte financeiro de programas de seguridade social e transferência de renda tem grande importância na composição da renda da maioria dos grupos domésticos em Rio de Peixes, sendo o Bolsa Família o mais difundido, recebido por $43,24 \%$ destes. O Seguro-Defeso é recebido por $35,13 \%$, sendo o mesmo recebido pelo casal em 5,4\%. A aposentadoria é recebida por um membro em $18,91 \%$ dos casos, e por dois membros em 5,4\%, mesma proporção em que era recebido o auxílio-maternidade.

Mesmo sendo o Bolsa Família o programa com maior alcance entre os grupos domésticos em Rio de Peixes, em termos de valores absolutos dos aportes monetários, esse benefício se encontra atrás da aposentadoria rural e também do Seguro-Defeso.

\footnotetext{
${ }^{3} \mathrm{O}$ ex-superintendente da pesca no Pará, que ocupou o cargo justamente na época do grande aumento nas afiliações e nos benefícios concedidos e que fez sua campanha para deputado estadual em 2010 baseada no segmento pesqueiro, foi eleito e teve seu mandato cassado por abuso político, econômico e uso da máquina pública na campanha eleitoral desse mesmo ano, pelo Tribunal Regional Eleitoral (TRE/PA).
} 
Somando-se à renda de todos os programas de seguridade social e transferência de renda recebidos em um ano em Rio de Peixes, estes somam pouco menos que a metade da renda obtida com a venda de farinha.

Os recursos advindos do Seguro-Defeso foram utilizados na seguinte ordem de importância: i) compra de materiais a serem utilizados nos processos de trabalho (pesca, agricultura e beneficiamento da mandioca e do açaí); ii) despesas para o grupo doméstico (comida, eletrodomésticos e remédios) e iii) pagamento de dívidas. Outros usos do recurso foram indicados com menor frequência. Como visto, há um arranjo que privilegia simultaneamente a reposição dos insumos para permitir as atividades tanto no longo como também no curto prazo, garantindo, assim, as condições para a reprodução social do grupo (ALMEIDA, 1986).

\subsection{O Seguro-Defeso e a Pesca: mudança na} QUANTIDADE PESCADA, NO JEITO DE PESCAR OU DE VER A PESCARIA?

Apesar de o Seguro-Defeso fazer parte de um programa de políticas públicas voltado à conservação ambiental, Teixeira e Abdallah (2008) e Maia (2009) apontam a possibilidade de o Seguro-Defeso estimular o esforço de pesca. No caso estudado, não constatamos esse esforço, muito embora tenha havido a generalização do uso da autodesignação de pescador artesanal em decorrência do recebimento do Seguro-Defeso ${ }^{4}$. Nenhum entrevistado citou ter começado a comercializar peixes em decorrência da afiliação à Colônia de Pescadores, permanecendo a pesca como atividade relacionada ao aprovisionamento, como tradicionalmente praticada.

4 Esta questão é especificamente debatida no artigo "O Seguro Defeso e o uso comum dos recursos naturais numa comunidade ribeirinha do Pará" (PEREIRA; MOTA, 2012).
O Seguro-Defeso, enquanto uma política de viés conservacionista, influenciou na socialização das ideias associadas à gestão coletiva dos recursos pesqueiros e na relação simbólica e factual dos moradores no que concerne ao respeito ao período do defeso, à quantidade pescada e ao estoque.

Com relação à compra de materiais de pesca com recursos do Seguro-Defeso, é certo que isso pode facilitar a pesca para os moradores da localidade, o que não implicaria necessariamente o aumento do esforço de pesca. Os referidos materiais têm o objetivo central de diminuir as dificuldades do trabalho, no sentido de que os pescadores possam praticá-la dentro das normas de sustentabilidade.

Outra mudança que está ocorrendo, relacionada ao intuito de manter a filiação à colônia, é a criação de peixes, atividade que teria sido proposta pela própria colônia. Porém, os dirigentes do órgão reconhecem problemas com a assistência técnica.

As diferentes iniciativas denotam o interesse de alguns moradores em permanecer filiados à Colônia de Pescadores e legitimar a identificação enquanto pescadores artesanais, de forma a assegurar o acesso ao benefício. Em decorrência, amplia-se o rol das estratégias mobilizadas para a reprodução social.

\subsection{O SEguro-DEFESO E A ROÇA: MENOR ESFOR- ÇO, PAGAMENTO DE MÃo dE OBRA E "VOlTA" À TER- RA}

Por ser a agricultura, especialmente a produção de mandioca para a transformação em farinha, a principal atividade econômica desenvolvida na localidade, alguns moradores investiram parte do dinheiro do Seguro-Defeso nessa atividade. Para eles, é no incentivo à agricultura que reside a maior importância do benefício, como afirma uma moradora: 
[...] então isso que eu vejo, assim, que eles usam o dinheiro que recebem de uma entidade pra ajudar num outro trabalho, né, porque você vê que aqui a pesca não funciona realmente, né. [...] A pesca ajuda mais pra agricultura. Porque através disso as pessoas compram motor pra beneficiar mandioca, né, esses motorzinhos pra usar pra beneficiar mandioca, boi pra carrear mandioca, e é assim, pagam às vezes trabalhador pra ir pra roça, pra trabalhar em outros lugares, né. (L 28, mulher, 49 anos).

Entre os entrevistados cujo grupo doméstico contava com pelo menos um membro que já havia recebido o Seguro-defeso em alguma ocasião, 31,25\% indicaram ter utilizado parte do dinheiro para algum investimento em agricultura, percentual bem menor do que os $68 \%$ que adquiriram materiais para incrementar a pesca. A explicação está relacionada à ideia de que há necessidade de comprar materiais de pesca para assim "efetivar simbolicamente" a condição de pescador artesanal diante dos agentes públicos e da própria comunidade. Isso se deve a um conflito em torno da "correção ética" em se filiar à colônia e receber o Seguro-Defeso.

Entre aqueles que, direta ou indiretamente, aplicaram parte do benefício em atividades ligadas à produção agrícola estão dois que afirmaram ter investido em atividades nos seus roçados, dois, na compra de motor para triturar mandioca e um que comprou mais terra. Os dois primeiros utilizaram o dinheiro para pagar a preparação da área e o plantio, conjunto de atividades frequentemente citado como mais trabalhoso e, geralmente, realizado localmente por meio de “convidados" (mutirão), modo de ajuda mútua baseado na reciprocidade. Ademais, fizeram roças maiores. Se feitos por "convidados", não seriam muito extensos. Isso se explica pelo fato de todos trabalharem ao mesmo tempo no roçado um dos outros, preparando áreas que variam de cinco a seis tarefas (50X50 m).

O trabalho em mutirão permite aos campone- ses preparar áreas de roça maior do que conseguiriam somente com os membros do grupo doméstico. Anda assim, é importante ter mão de obra familiar para ter maior participação nos "convidados". Em outros casos, é necessário o pagamento de trabalhadores temporários, com considerável gasto para o contratante, como explicitado:

E já teve ajuda aqui, no meu trabalho mesmo, né, pra eu fazer, olha, esse roçado aí, tive um gasto bonito, um gasto bom, aí foi através disso [Seguro-Defeso] já, né, que eu tive essa condição financeira já... pra investir lá, né. (A2, homem, 34 anos).

Esses serviços foram realizados por meio da contratação de jovens do sexo masculino da própria localidade, seja através de diárias ou empreitadas. Essa estratégia, de venda de força de trabalho, é recorrente entre os membros de alguns grupos domésticos que almejam a obtenção de dinheiro mais rapidamente.

Outra modificação importante na agricultura local com expressão nos últimos anos é a utilização de motor acoplado em um ralo cilíndrico para triturar a mandioca, regionalmente conhecido como "catitu"'s. Dois moradores entrevistados disseram ter usado o dinheiro do Seguro-Defeso para comprar o equipamento:

Isso aí também, né, o pessoal da pesca, eles fizeram também, compraram assim um motorzinho pra bater mandioca, esse meu sobrinho comprou disso, que é da pesca, ele comprou o motorzinho (M32, mulher, 35 anos).

Em Rio de Peixes essa é uma tecnologia que apenas recentemente está sendo adotada com recursos do Seguro-Defeso e outros benefícios sociais, principalmente no que se refere ao uso do motor, como ${ }^{5}$ Citado por Wagley (1988) em obra publicada pela primeira vez em 1953. 
confirmam os depoimentos:

Pesquisador: $O$ motor de bater tem muito tempo que o pessoal usa?

L27: Não, foi há pouco tempo.

Pesquisador: Há quanto tempo começou a ter esses motores?

G30: Olha, faz uns quantos tempo, só que nós pra cá pra dentro mesmo é que não faz muito tempo que nós começamos, até porque é mais difícil pra comprar, e um motor desse, agora mudou... (G30, homem, 24 anos).

O uso do "catitu" possibilita ao produtor utilizar uma mistura da mandioca que esteve de molho, chamada de "mole", com aquela que foi apenas colhida e descascada, a "dura", de maneira rápida e eficiente. Essa prática aumenta o rendimento do trabalho no processamento da farinha, como explicitado por entrevistados:

Até que um motorzinho desses ajuda muito, ainda mais quando é só duas pessoas pra trabalhar na farinha assim. Porque se não for com o motor a pessoa não tem nem tempo quase pra comer, tem que comer mexendo a farinha (M32, mulher, 35 anos).

[...] com o tempo que tu botava pra fazer dois, tu fazia dois. Agora se tu botar pra fazer dois e quiser fazer quatro, faz quatro. Foi isso que foi a diferença agora (G30, homem, 24 anos).

Outra forma de uso que não foi citada por nenhum dos beneficiários do Seguro-Defeso e também se refere a trabalho agrícola foi indicada por uma não afiliada à colônia: é a compra de mantimentos para a realização de "convidados":

Com esse dinheiro compra a despesa pra comer, um dia a minha cunhada falou assim: vamos aproveitar esse salariozinho pra gente capinar a roça. Quer dizer, recebeu o Seguro-Defeso, mas foi pra roça. Capinar, pra ajeitar... (L28, mulher, 49 anos).

Os moradores de Rio de Peixes, que fizeram uso de parte dos recursos do Seguro-Defeso para auxiliar na produção agrícola, utilizaram-se de estratégias semelhantes às constatadas por Delgado e Cardoso Jr. (1999, p. 9). Esses autores verificaram que moradores do Sudeste e Nordeste do Brasil estariam fazendo uso do seguro previdenciário rural, em especial as aposentadorias, como seguro agrícola, visto que aquele propicia um excedente que seria "praticamente reinvestido na própria atividade produtiva familiar, criando condições para uma 'reprodução ampliada' dessa economia familiar". Esse resultado foi corroborado pela pesquisa de Caldas, Anjos e Bezerra (2007), no sul do Brasil, que aponta para a utilização dos recursos da aposentadoria rural na agricultura em mais da metade dos estabelecimentos pesquisados.

A comparação realizada no parágrafo anterior serve para ilustrar a utilização de rendas extras à produção no Brasil, visto que existem muitas diferenças entre um e outro benefício (periodicidade, faixa etária do beneficiário). As especificidades de cada benefício implicam em grandes diferenças entre os grupos domésticos dos beneficiados, mas algumas semelhanças podem ser constatadas, como o uso de parte dos recursos para a produção agrícola.

O Seguro-Defeso está sendo utilizado por alguns beneficiários para auxiliar na produção agrícola, seja de forma a diminuir o esforço e o tempo de trabalho, com a compra de instrumentos para a fabricação da farinha, seja com a contratação de trabalhadores temporários, ou até com a compra de terra para trabalhar, servindo assim como forma de capitalização agrícola. 
3.3. O Comércio e o Seguro-Defeso: reproDUÇÃO E DIFERENCIAÇÃO

Parte importante dos gastos realizados com o dinheiro do Seguro-Defeso é realizada na sede municipal onde se situa o local de recebimento do benefício. Ali, são adquiridos mantimentos, materiais de pesca, motores (para gerador de energia ou barco) e demais produtos sob o argumento de que custam mais barato do que na localidade. É consenso que, de maneira geral, sobra um pouco do recurso para uma necessidade:

A gente não traz já quase nada, porque a gente já tinha de ir lá receber né, gastando dinheiro com passagem. [...] Ainda sobra um pouco pra gente resolver alguma coisa por aqui (G30, homem, 24 anos).

A forma como o benefício foi recebido, integralmente ou parcelado, influencia na maneira como o mesmo é gasto. A maioria dos segurados afirmou preferir receber o valor de forma integral, como ocorreu algumas vezes devido a atrasos no pagamento do benefício, e não parcelado durante os meses do defeso, como prevê a legislação.

A explicação recorrente para a preferência no recebimento do Seguro-Defeso de forma integral é relacionada aos gastos com deslocamento, que aumentam quanto maior for o número de parcelas a receber. Alguns também alegaram preferir receber o total porque assim seria melhor para investir: "Se fosse de uma vez era melhor, que o cara já sabia o que ele comprava" (G30, homem, 24 anos). Exceção é um dos beneficiários que afirmou preferir receber o Seguro-Defeso parcelado, pois acredita que, ao receber tudo de uma vez, gastaria o dinheiro mais rapidamente.

Dentre os beneficiários do Seguro-Defeso, $18,75 \%$ afirmaram ter investido parte do recurso em atividades diretamente ligadas ao comércio, quais se- jam, a aquisição de uma máquina de processar açaí para beneficiar e comercializar parte de sua produção na época da safra e também alugá-la a outros produtores; a compra de um freezer para congelar frangos e vendê-los na localidade; e a compra de um carregamento de farinha para vender a comerciantes que a revendem na cidade, atividade esta desenvolvida por alguns moradores da beira.

Os investimentos realizados em atividades comerciais apontam para a tendência de diferenciação econômica. Em estudo realizado em comunidade no Maranhão, Soares (1981) descreveu a economia por meio da combinação de atividades direcionadas ao consumo, à venda e à acumulação (gado e comércio). Naquele contexto, a combinação das atividades é a estratégia que traz a possibilidade de "ruptura do curso de pauperização", e o comércio, destaca o autor, é a principal fonte de diferenciação econômica. Ressaltando as particularidades e o momento histórico, observamos em Rio de Peixes a combinação de atividades para superar a pobreza, desta feita, com o aporte de recursos oriundos do Seguro-Defeso.

Curiosamente, o comércio local não experimenta dinamismo em Rio de Peixes. Os comerciantes ali situados afirmaram a princípio que não haviam notado diferença com o advento do Seguro-defeso. Aliás, há o reconhecimento de que as vendas diminuem um pouco nos dias subsequentes ao recebimento do benefício e logo se normalizam. Já a esposa de um comerciante com estabelecimento similar afirmou que o comércio local só melhora nos primeiros dias, pois logo o dinheiro acaba.

Alguns componentes influenciam na perspectiva que os comerciantes têm sobre a melhora ou piora na venda. Para algumas mercadorias, a expectativa é que a venda piore, pois os beneficiários fazem compras na cidade no período em que vão retirar o dinheiro, motivados pelos preços mais baratos que os praticados na localidade. Já para outros produtos, as vendas têm possibilidades de melhora por serem 
ocasionalmente consumidos, como o açaí, pequenos produtos industrializados, como biscoitos e balas, e produtos perecíveis em geral, com vendas incrementadas pelo restante do dinheiro que está em posse do beneficiário.

No âmbito do comércio, o dinamismo do mercado de venda e compra de barcos com motor de popa, que oferece especial mobilidade nos igarapés (chamados localmente de rabudos), foi citado por diversos moradores. Essa mudança foi mais relatada entre aqueles não afiliados à Colônia de Pescadores. Um morador (B18, homem, 56 anos) chegou a dizer que "agora tem mina de motor de rabo", referindo-se à grande quantidade do referido equipamento na forma usual de falar localmente, fazendo analogia com o que é encontrado na natureza.

Não é provável que todos os barcos com motor foram comprados com recurso do Seguro-Defeso, pois, entre os seus afiliados, somente dois afirmaram ter comprado o equipamento. Entretanto, como essa é uma mudança que ocorreu nos últimos anos, muitos fazem essa associação. A disseminação dos barcos a motor acarreta ainda o aumento da venda de combustíveis pelos comerciantes da localidade.

Ainda com relação a veículos de mobilidade, cinco beneficiários do Seguro-Defeso informaram ter comprado canoa ("casquinho") com parte do dinheiro do benefício. Esse meio de transporte é de extrema relevância porque os caminhos são por água durante todo o ano e, principalmente, na época da cheia. Ademais, a compra desse produto movimenta a economia local porque são feitos por um morador de localidade próxima, seja por encomenda direta do próprio comprador ou de um comerciante local, que assim pode revendê-lo. Além do mais, como o fabricante das embarcações passa alguns dias na localidade para fazê-las, parte do dinheiro recebido é gasto nos comércios da beira.

\subsection{O futuro: quais os planos com o Segu- RO-DEFESO?}

Alguns moradores fazem planos para a utilização dos próximos benefícios a receber, sendo um dos mais recorrentes a ideia de comprar um "motor rabudo". Um beneficiário afirmou querer investir na compra de um casco e um desses motores, e como cada um deles custava aproximadamente $\mathrm{R} \$ 1.000,00$, seria investido todo o recurso oriundo do benefício. Outros indicaram querer investir parte do dinheiro do próximo Seguro-Defeso em motores geradores de energia, e há também aqueles que investiram anteriormente na roça e pretendem fazer novamente esse uso. Enfim, a certeza do recebimento do recurso povoa o imaginário de todos, que fazem planos.

Mas não são todos os que receberam alguma vez o Seguro-Defeso que fazem planos para a utilização do próximo. Um casal, cujos cônjuges se filiaram à Colônia de Pescadores na mesma época, mas só a esposa já havia recebido o benefício por duas vezes, evidencia o porquê da percepção de muitos sobre a inconstância da participação dos moradores de Rio de Peixes nessa política. A esposa (N31, mulher, 26 anos) afirmou que ainda não pensou o que vai fazer com os próximos benefícios a receber, porque "às vezes faz os planos e fica só na vontade", ou seja, o medo de ter frustrados seus planos faz com que o planejamento seja contido.

Independentemente de quais sejam as expectativas quanto ao futuro, reconhecemos a vulnerabilidade do PSDPA e dos seus afiliados. Só uma legislação específica para a categoria social na qual esse grupo está inserido, o de camponeses que realizam múltiplas atividades, dentre as quais, a pesca, poderia levar a concepção de estratégias de reprodução diferenciadas no longo prazo.

O fato é que o Seguro-defeso trouxe uma diversidade de mudanças e novas possibilidades na 
comunidade de Rio de Peixes, impulsionando uma circulação monetária de bastante relevância para a vida local. Além disso, foram construídas novas compreensões sobre as identidades individuais e coletivas e a proteção de recursos naturais de uso comum.

\section{Conclusões}

O tema central deste artigo foi a reprodução social de grupos domésticos camponeses a partir da influência da afiliação, de um ou mais dos seus membros, à colônia de pescadores, o que lhes permitiu a possibilidade de recebimento do Seguro-defeso.

A principal fonte de recursos para a maioria dos grupos domésticos é a produção de farinha de mandioca, sendo também percebido um aumento de importância na economia local de recursos advindos de programas de políticas públicas voltados à seguridade social.

Nessa esfera dos programas de seguridade social, cresceu localmente em importância a Política de Seguro Desemprego ao Pescador Artesanal, no início da década de 2010. O princípio fundamental dessa política é garantir o sustento do pescador artesanal durante o período de proibição da pesca de determinadas espécies para que se proteja o seu momento de procriação.

Um número significativo de moradores resolveu optar, no conjunto das estratégias de reprodução social, pela adoção da autoidentificação de Pescador Artesanal para afiliar-se à Colônia de Pescadores, o que os torna aptos a receberem o Seguro-defeso.

As afiliações à Colônia de Pescadores, necessárias nesse caso para o recebimento do Seguro-defeso, foram realizadas de forma bastante flexibilizada, por estarem os agentes envolvidos na execução e suporte, além dos beneficiários, interessados que estas ocorressem, embora sob diferentes perspectivas. Essa situação foi favorecida pela falta de estrutura do governo em cobrir a implantação e fiscalização do programa in loco.

A entrada na Colônia de Pescadores e o recebimento de Seguro-Defeso por parte de alguns moradores levou a alterações na relação simbólica e factual dos moradores com relação à gestão de recursos pesqueiros no que concerne ao respeito ao período do defeso, à quantidade pescada e à quantidade de pescado disponível.

O conjunto de percepções relativas a mudanças ou continuidades que mais apresenta vieses é, sem dúvida, aquele sobre o respeito, ou não, ao período do defeso por parte dos moradores de Rio de Peixes. Porém é de se notar que tanto os que achavam que nada havia mudado após o Seguro-defeso quanto os que viam mudanças a partir deste achavam importante a regra da época do defeso para o desenvolvimento dos peixes.

A Política de Seguro Desemprego ao Pescador Artesanal tem então a possibilidade de trazer novas perspectivas ambientais com relação ao respeito ao período do defeso na localidade de Rio de Peixes, o que não indica que será dessa forma resolvido o problema de escassez de peixes que figura na localidade há aproximadamente 30 anos, visto que outras práticas mais danosas devem ser levadas em consideração, como pescarias industriais que ocorrem nessa bacia e a retirada de seixo do leito do rio.

Assim, o que está em jogo são menos as práticas reais e mais as interpretações de um discurso veiculado por um programa de política pública. Há uma tendência para associar uma maior conservação ao Seguro-Defeso, mas sem a problematização da extinção de algumas espécies já anteriormente ocorridas na região, nem o reconhecimento da existência de um sistema de regras que garantiu a existência dos recursos até pouco tempo. 
Mesmo tendo sido a compra de materiais de pesca a utilização do Seguro-defeso mais citada entre os moradores de Rio de Peixes, não parece ocorrer um aumento na quantidade pescada. $\mathrm{O}$ que parece acontecer é a melhora na qualidade da pesca, realizada com menor esforço e gasto de tempo. Porém, foi demonstrado que tal gasto pode também estar ligado a uma ideia predominante da necessidade de se comprar materiais de pesca, se reafirmando assim enquanto pescador, tanto diante das instituições legais envolvidas, como também localmente, ou seja, entre os próprios membros da comunidade.

Em se tratando da reprodução social, os recursos oriundos do Seguro-defeso foram utilizados diretamente na reprodução social de ciclo curto e geracional, alcançando as atividades de pesca, agrícolas, beneficiamento de produtos e comércio.

Os materiais de pesca concentraram o maior investimento, quer seja para diminuir a penosidade do trabalho, quer seja para constituir o modelo correspondente ao que propugna a legislação quanto ao que significa ser pescador artesanal.

$\mathrm{Na}$ agricultura, concluímos que o investimento dos recursos advindos do Seguro-defeso foi destinado especialmente para a intensificação da capacidade de implantação de roças para a produção de mandioca, produto que garante o alimento consumido diariamente, a farinha, e reafirma uma das identidades correlatas ao que é ser camponês na Amazônia.

O beneficiamento de produtos teve um significativo impulso com os recursos do Seguro-defeso. O processamento da farinha e do açaí, combinando o conhecimento tradicional com recursos tecnológicos disponíveis no formato de máquinas, contribuíram para tornar os processos menos penosos e mais eficientes quanto ao volume de processamento. $\mathrm{O}$ uso do Seguro-defeso está trazendo a possibilidade de se diminuir o esforço de trabalho na produção de farinha, além de possibilitar um incremento na renda que objetivamente dá melhor condição de consumo para os grupos domésticos dos beneficiários, permitindo a compra de produtos de uso doméstico e também de investimentos na produção.

Em se tratando do comércio, a disponibilidade do recurso incentivou iniciativas de comercialização (açaí, frango e "casquinhos"). As atividades compõem arranjos cujos propósitos, a curto prazo, é o aprovisionamento do grupo doméstico e, a longo prazo, a estabilidade indispensável à reprodução social como camponeses que realizam inúmeras atividades.

Mesmo que todos eles estejam submetidos á mesma política, quando comparados entre si e em relação aos demais moradores, concluímos que estão sendo postos em prática processos de diferenciação econômica.

Notamos a intenção de alguns moradores em permanecer filiados à Colônia de Pescadores e legitimar a identificação enquanto pescadores artesanais, de forma a assegurar a inserção em políticas públicas direcionadas a essa categoria. Em decorrência, amplia-se o rol das estratégias de reprodução social por eles mobilizadas.

Apesar de alguns moradores indicarem mudanças nos sistemas de produção, relação com a natureza e interações sociais, estas não estão relacionadas a uma efetiva mudança de categoria social do grupo estudado, sendo a reprodução social desse grupo, com suas especificidades nas relações pessoais e com o ambiente que está em cena.

Para finalizar, o recebimento e uso do Seguro-defeso representa uma contribuição para uma mudança qualitativa na reprodução social, ao diminuir a penosidade associada ao esforço físico em atividades agrícolas e na pesca, ou ao proporcionar ganho extra, através dessas atividades ou de atividades comerciais. Este, porém, é um programa de política pública que está sendo apropriado pelos moradores de Rio de Peixes de uma forma que transcende sua concepção, 
o que demonstra a necessidade de políticas públicas que sejam voltadas especificamente para este público, camponês ribeirinho amazônico, que pratica uma diversidade de atividades produtivas.

\section{Referências bibliográficas}

ALMEIDA, M. W. B. Redescobrindo a família rural. Revista Brasileira de Ciências Sociais, v.1, n.1, p. 6683, 1986.

ALMEIDA, R. Amazônia, Pará e o mundo das águas do Baixo Tocantins. Estudos Avançados, v. 24, n. 68, p. 291-298, 2010.

CALDAS, N. V.; ANJOS, F. S. dos; BEZERRA, A. J. A. Envejeciendo em la pobreza? Universalización de los derechos sociales em la agricultura familiar del sur de Brasil. Trayectorias Revista de Ciencias Sociales de la Universidad Autonoma de Nuevo Leon, v. 9, n. 25, p. 78-88, 2007.

CARNEIRO, E. F. et al. Estratégias de comercialização dos agricultores familiares em comunidades ribeirinhas. In: FRAXE, T. J. P.; PEREIRA, H. S.; WITKOSKI, A. C. (Org.) Comunidades ribeirinhas amazônicas: modos de vida e uso dos recursos naturais. Projeto PIATAM mar (Brasil). Manaus: EDUA, 2007. p. 199 - 215.

COTRIM, D. C.; MIGUEL, L. A. Pluriatividade: uma noção aplicável em pescadores artesanais? In: ENCONTRO DE ECONOMIA, 2008, Porto Alegre. Anais... Porto Alegre: EDIPUCRS, 2008.

DELGADO, G. C.; CARDOSO JUNIOR, J. C. O idoso e a previdência rural no Brasil: a experiência recente da universalização. Rio de Janeiro: IPEA, 1999.

FRAXE, T. J. P. Homens anfíbios: etnografia de um campesinato das águas. 2. ed. São Paulo: Annablume, 2011.

GARCIA, B.; OLIVEIRA, O. La familia y el trabajo: principales enfoques teóricos e investigaciones sociodemográficas. In: TOLEDO, E. de La G. (Coord.). Tratado latinoamericano de sociologia. Barcelona: Anthropos Editorial; México: Universal Autónoma Metropolitana, 2006. p. 148-170.

GODOI, E. P.; MENEZES, M. A. de; ACEVEDO
MARIN, R. E. Diversidade do campesinato: expressões e categorias. São Paulo: Editora UNESP; Brasília, DF: NEAD, 2009. 2 v., p. 9 - 36. (História social do campesinato no Brasil).

HÉBETTE, J.; MAGALHÃES, S. B.; MANESCHY, M. C. Introdução: contemporaneidade do campesinato na Amazônia Oriental. In: HÉBETTE, J.; MAGALHÃES, S. B.; MANESCHY, M. C. (Org.) No mar, nos rios e na fronteira: faces do campesinato no Pará. Belém, PA: EDUFPA, 2002.

INSTITUTO BRASILEIRO DE ANÁLISES SOCIAIS E ECONÔMICAS. Repercussões do programa bolsa família na segurança alimentar e nutricional das famílias beneficiadas: documento síntese - junho de 2008. Rio de Janeiro, [2008]. 20 p.

LOURENÇO, C. F.; HENKEL, J. A. S.; MANESCHY, M. C. A seguridade social para pescadores artesanais do Brasil: estudo de caso no Pará. Belém, PA: ICFS, 2006. 59 p.

MAIA, M. B. R. Do defeso ao seguro desemprego do pescador artesanal: a inclusão do pescador nas políticas públicas de seguridade social. 2009. $94 \mathrm{f}$. Dissertação (Mestrado em Sociologia) - Instituto de Ciências Humanas e Letras, Universidade Federal do Amazonas, Manaus.

MARINHO, M. S. Pesca artesanal, defesos de pesca e unidades de conservação. In: ENCONTRO NACIONAL DE ANTROPOLOGIA DO DIREITO, 1., 2009, São Paulo. Anais... São Paulo: Universidade de São Paulo, 2009.

MCGRATH, D. G. et al. Diagnóstico, tendências, potencial, estrutura institucional e políticas públicas para o desenvolvimento sustentável da pesca e aquicultura. In: DIAGNÓSTICO da Pesca e da Aquicultura no Estado do Pará. Belém, PA: SEPAQ, 2008. v. 7, $117 \mathrm{p}$.

MOREIRA, L. F. C. Do comum ao privado: as transformações quanto aos principais usos da floresta na comunidade Santa Maria Assentamento Olho D'Água II, município de Moju/PA. 2009. 160 f. Dissertação (Mestrado) - Universidade Federal do Pará, Programa de Pós-Graduação em Agriculturas Amazônicas, Belém, PA.

MOREIRA, E. S.; HÉBETTE, J. Metamorfoses de um campesinato nos Baixo Amazonas e Baixo Xingu Paraenses. In: GODOI, E. P.; MENEZES, M. A.; 
MARIN, R. A. (Org.) Diversidade do campesinato: expressões e categorias. São Paulo: Editora UNESP; Brasília, DF: Núcleo de Estudos Agrários e Desenvolvimento Rural, 2009. V.I, p. 187 - 207.

NEVES, D. P. Reforma agrária esforçada, In: SIMPÓSIO IMPASSES E DILEMAS DA POLÍTICA DE ASSENTAMENTOS - BALANÇO DE 20 ANOS, 2005, São Paulo. Anais... São Paulo: UNIARA, 2005.

NIEDERLE, P. A. et al. Pluriatividade e pesca artesanal: o caso da Colônia Z-3 em Pelotas, RS. In: CONGRESSO DA SOCIEDADE BRASILEIRA DE ECONOMIA, ADMINISTRAÇÃO E SOCIOLOGIA RURAL, 43., 2005, Ribeirão Preto. "Instituições, Eficiência, Gestão e Contratos no Sistema Agroindustrial”: anais. Ribeirão Preto, SOBER, 2005.

PEREIRA, J. A. G.; MOTA, D. M. O seguro defeso e o uso comum dos recursos naturais numa comunidade ribeirinha do Pará. In: ENCONTRO NACIONAL DA ANPPAS, 6., 2012, Belém, PA. Anais... Belém, PA: [ s. n.], 2012.

PINTOM, F.; EMPERAIRE, L. Agrobiodiversidade e agricultura tradicional na Amazônia: que perspectivas? IN: SAYAGO, D.; TOURRAND, J.-F.; BURSZTYN, M. (Org.). Amazônia: cenas e cenários. Brasília, DF: Editora Universidade de Brasília, 2004. 380 p.

SABOURIN, E. Camponeses do Brasil: entre a troca mercantil e a reciprocidade. Tradução: Leonard Milani. Rio de Janeiro: Garamound, 2009. 336 p.

SCHNEIDER, S. Teoria social, agricultura familiar e pluriatividade. Revista Brasileira de Ciências sociais, v. 18, n. 51, p. $1-18$, fev. 2003.

SOARES, L. E. Campesinato: ideologia e política. Rio de Janeiro: Zahar editores, 1981. p. 73 - 109.

TEIXEIRA, G. S.; ABDAlLAH, P. R. Política de seguro-desemprego ao pescador artesanal: assistencialismo ou incentivo? In: CONGRESSO DA SOCIEDADE BRASILEIRA DE ECONOMIA, ADMINISTRAÇÃO E SOCIOLOGIA RURAL, 46., 2008, Rio Branco. Apresentação oral. Rio Branco: [s. n.], 2008. 12 p.

WAGLEY, C. Uma comunidade amazônica. 3. ed. São Paulo: Universidade de São Paulo, 1998. 